\title{
On normative cognition, and why it matters for cognitive pragmatics
}

\author{
ANTONELLA CARASSA and MARCO COLOMBETTI
}

Abstract

In Cognitive pragmatics: The mental processes of communication (2011), Bruno Bara presents a detailed summary of a theory of human communication, called "cognitive pragmatics," which he has been developing since the 1980 s together with a number of colleagues, and has been presented in several scientific articles and in a recent book (Bara 2010). The basic tenets of this theory are that communication is a cooperative activity, in which human agents engage intentionally, and that for communication to take place successfully all the participants must share certain mental states. Coherently with these assumptions, cognitive pragmatics aims at clarifying what mental states are constitutive of communication, and what cognitive structures underlie the cooperative activities involved in communication.

To this position we are strongly sympathetic. However, we think that the theoretical framework currently offered by cognitive pragmatics is inadequate to account for the cooperative nature of human communication. In particular, we believe that to deal with human cooperation, the types of mental states considered by cognitive pragmatics should be extended; that the concepts of conversation and behavior game do not adequately explain the dynamics of human communication; and that the role of communicative intentions is not sufficiently clarified.

In this commentary we first discuss the issue of collective activities (Section 1). Next we consider some problems related to conversation and behavior games (Section 2), and bring in the issue of normativity, that we consider as a crucial component of human interaction (Section 3). We then discuss the relationship between communicative intentions and normativity (Section 4), and finally draw some conclusions (Section 5). 


\section{Collective action}

Cognitive pragmatics aims at modeling conversational exchanges: In this context, Bara is certainly right in considering communication as a kind of cooperative activity. However, the types of mental states and cognitive structures upon which cognitive pragmatics is based appear to be insufficient to deal with human cooperation.

Since the 1980s, much effort has been devoted to the understanding of cooperative activities. Interesting proposals have been put forward both in philosophy, in the area of collective intentionality, and in psychology, in the areas of joint action and intersubjectivity. Of course it would be very difficult, if not impossible, to take all these proposals into account in a single theory of human communication; but considering the level of abstraction at which human cognition is modeled by cognitive pragmatics, at least the work carried out in the area of collective intentionality, appears to be very relevant. In particular, the philosophers working in this area (like Raimo Tuomela, Margaret Gilbert, John Searle, Michael Bratman, and several others) have submitted different analyses of what doing something together amounts to. While there is no universal consensus on a specific proposal, most authors agree that personal intentions, even in presence of shared beliefs, are not sufficient to account for collective action (see, for example, Tollefsen 2004 and Roth, 2010).

Even if there is still no universally accepted theory of collective action, the idea of doing something together is so central to cognitive pragmatics that the issue should not be ignored. In particular, we think it is important to take a definite position on whether collective action does or does not involve normative relationships between the agents. Our view is that it does, and for this reason we are sympathetic with the approach to collective action put forward by Margaret Gilbert, and in particular with her concept of joint commitment (Gilbert 1989, 1996, 2000). Different views on this matter are of course possible, but, as we shall try to show in the sequel, taking a motivated position on the role of normativity is of fundamental importance for any theory of human communication.

\section{Cooperation and games}

A major feature of cognitive pragmatics is the distinction between two different levels of cooperation in human communicative interactions, namely, conversational and behavioral cooperation; for example, an addressee who explicitly denies a request is refusing to cooperate at the behavioral level, but is still cooperating at the conversational level, while an addressee that completely ignores a request is refusing to cooperate at the conversational level. We think 
it is fair to say that, according to cognitive pragmatics, conversational cooperation requires the interlocutors to play the conversation game and to share the relevant behavior games, and behavioral cooperation additionally requires the interlocutors to play the relevant behavior games.

There are aspects of this approach that we find unconvincing. At first perplexity concerns the sharp asymmetry in the levels of abstraction at which the two types of games are treated. Behavior games are described as action plans actually shared by the interacting agents; as such being situated at what we may call the "conceptual level," that is, the level at which agents are aware of the actions that can be performed in the world (like making coffee or running the departmental activities). On the contrary, the conversation game is described in terms of metarules that control the chaining of certain cognitive processes involved in understanding a communicative act and in planning a response; as such, the conversation game situates itself at what we may call the "competence level," in that it concerns mental processes of which agents are typically unaware. Now, we wonder whether there would also be something important to say about behavioral interactions at the competence level, and about conversational interactions at the conceptual level.

In our view, the competence level of behavioral interaction concerns the cognitive capacities that are involved in doing something together. Therefore, the fact that cognitive pragmatics does not cover this aspect is not surprising, in view of what we said in the previous section: No theoretical framework is offered to deal with collective action.

Now, what about the conceptual level of conversation? In cognitive pragmatics, the conversation game is in charge of accounting for conversational cooperation. As we have remarked, it consists of metarules that control the chaining of the mental processes involved in understanding and planning communicative acts; in particular, such metarules dictate that an agent is to produce a response by generating a communicative intention and planning a communicative act. By themselves, however, these metarules do not achieve conversational cooperation: They only guarantee that some response will be produced. But, of course, not all possible responses are conversationally cooperative. Possibly, the role of achieving conversational cooperation could be played by conversation games formulated at the conceptual level, which, as we have previously observed, are presently not part of cognitive pragmatics. Such games may account for the fact that conversational cooperation poses different requirements in different types of conversation: for example, the kind of conversational cooperation expected in a sociable conversation differs from the one expected in a session of talk work.

Another possibility, of course, is that the distinction between conversational and behavioral cooperation is simply dropped. Indeed, we believe that there is only one concept of cooperation, which can be defined in the context of a 
suitable theory of collective action. In turn, collective action requires agents to perform individual acts, either in synchrony or in turns, and such acts may or may not be communicative. Communicative acts typically involve the use of language, but of course non-linguistic communicative acts are possible and common: What makes an act communicative (and on this we agree with Bara) is the intention under which it is performed. Following this line of thought, conversational cooperation should be understood as a the specialization of general cooperation when communicative acts are involved; but to understand what makes such acts special in a cooperative activity, it is necessary to appreciate the specific role of communicative intentions in human interaction. We shall come back to this point in Section 4.

The main advantage of dropping the distinction between conversational and behavioral cooperation is that this allows one to treat in a unified way different types of interactions, which involve communication at different degrees. Certain types of cooperative activities, like playing a string quartet, require little communication between the agents; others, like children playing, involve a more substantial amount of communication; still other, like sociable conversation and talk work, entirely consist of communicative exchanges. The challenge, we believe, is to show that a theory of communication can be embedded in a general theory of cooperation, provided that the role of communicative intentions is fully appreciated. Certainly, the common ground is going to play a major role in any such theory, and, among other things, it is going to include shared knowledge of stereotyped interaction patterns, that we may well call "games." But we do not expect that these structures will play such a central role in a theory of human communication as they do in cognitive pragmatics (more on this in the next section).

\section{The issue of normativity}

In cognitive pragmatics, behavior games are defined as epistemic structures, that is, as shared knowledge of collective plans. It is interesting to note that, in discussing their role in communication, Bara makes wide use of normative terminology, for example (our emphasis): "that the game be playable," "bidding," "a game [ . . ] must be proposed and accepted by all those who commit themselves to taking part in it" (2011: 458); "agreed to play," "valid with respect to the context," "appropriate to the situation" (2011: 459). But, as we have already remarked, no conceptual tool for dealing with normativity is offered by cognitive pragmatics.

Apparently, Bara tries to reduce the normative aspects of interaction to the concept of social penalization, more specifically to expectations about possible punishments (2011: 459). However, relying on such concepts does not explain 
normativity away, because punishment is itself a normative concept (Carassa et al. 2008). The point is that punishment cannot be defined simply as a cost imposed by society, or by a group, to one of its members. The very concept of punishment implies that a cost is imposed because some norm has been violated, and this means that the concept of punishment cannot be used to explain normativity away.

In our opinion, normativity is a basic dimension of human cognition, together with the epistemic and volitional dimensions. In particular, we believe that normativity is crucial to understand human interactions; that the human capacity to understand and manage normative relationships presupposes certain cognitive abilities, presumably unique to the human species; and that the ability to create new normative relationships (like directed obligations, rights, and so on) is strictly related with the possibility of acting with communicative intentions (more on this in Section 4).

It must be said that the systematic neglect of normativity is not specific of cognitive pragmatics, but is a general problem of cognitive science. In particular, very few cognitivists seem to be aware of the importance of the normative dimension in order to understand communicative interactions. A notable exception is Michael Tomasello, who goes as far as to suggest that there is a substantial connection between normativity and communicative intentions (2008: 214):

One important function of the Gricean communicative intention-above and beyond the communicator alerting the recipient that she wants something from her-is that it essentially makes everything public, what some theorists call "wholly overt." This means that the norms apply and cannot be avoided.

However, Tomasello does not tackle the problem of what cognitive capacities are necessary to understand normativity, nor does he clarify why exactly there should be a special relationship between the application of norms and communicative intentions.

In moral psychology, normative cognition is defined as the "human capacity to understand norms and to make normative judgments" (Machery and Mallow 2010: 4). Though, what is central to human communication is not only the ability to understand existing norms and make normative judgments, but also the capacity to create new normative relationships. To clarify this point, let us consider an example. On a train, agent $A$ has the following exchange with agent $B$, a complete stranger:
(1) (a) A: "Would you mind if I close the window?"
(b) B: "Not at all."
(c) A: "Thank you."
(d) $A$ closes the window. 
How would cognitive pragmatics account for this interaction? First, we have to assume that a shared behavior game is exploited. But what does this game look like? If a behavior game is to specify only non-communicative acts, here the only element of the game is $A$ 's act of closing the window; but this would not look like a game at all: It is just one individual action, performed by one of the interlocutors. Therefore, we have to admit that the behavior game played by $A$ and $B$ also includes communicative acts, like asking for and granting permissions. This game may look like:

(i) $x$ asks $y$ for the permission to do an action

(ii) if $y$ grants $x$ the permission to do the action

then (iii) $x$ thanks $y$

(iv) $x$ does the action else $\ldots$

But how are we to complete the game in case the permission is denied? Should it account for all possible continuations of the interaction? This seems very difficult to achieve. And, above all, is a game-like structure really necessary to explain what goes on in Exchange 1?

We think it is not. The reason is that our understanding of the communicative acts of asking for a permission, granting a permission, and so on, is sufficient to determine the range of relevant responses that can be produced by a cooperative interlocutor: In our view, $A$ asking for the permission to close the window gives $B$ both the right and the obligation to take a definite position on $A$ 's action of closing the window; $B$ 's granting the requested permission gives $A$ both the right and the obligation to close the window; and so on. All this is just part of our common understanding of deontic concepts, and does not seem to require knowledge of a behavior game. Of course, the common ground is crucial to $B$ 's understanding that $A$ 's utterance $1 a$ is a polite indirect request for permission to close the window. But to this purpose it is sufficient that the interlocutors share enough knowledge of what types of acts require permission from others in a particular situation. In the case at hand, we can assume shared knowledge of general norms of the type, "To perform an action that directly affects the welfare of other agents, permission from these agents is required." Such norms are part of our normative common ground, but do not constitute "games" in any obvious sense.

Exchange 1 also shows an interesting interplay between what we may call "superpersonal" and "interpersonal" normativity (Carassa and Colombetti 2011): Social rules on when a permission is required are examples of superpersonal normativity; but the communicative transaction of Exchange 1 creates a brand new piece of interpersonal normativity, that is, a set of specific deontic relationships between $A$ and $B$, something akin to a temporary contract binding $A$ and $B$. Even when an interaction is very simple, like in our example, such 
relationships have far-reaching consequences; for example, after step $1 c$ it would be inappropriate for $A$ not to close the window, and immediately after step $1 d$ it would be inappropriate for $B$ to ask, "Would you mind if I open the window?"

The role of normativity in human communication has been widely recognized in the philosophy of language, for example in speech act theory (Alston 2000; Searle 2007) and in the tradition known as "pragmatism" (Brandom 1994; Kukla and Lance 2009). In our opinion, what current normative theories of communication mainly lack is due consideration for the collaborative process through which the interlocutors co-construct interpersonal normativity in conversational exchanges. To account for this aspect of interpersonal normativity, we have suggested that conversational interactions may be analyzed in terms of joint commitments, which in turn entail directed obligations and rights of the interlocutors (Gilbert 1986, 1996, 2000). More precisely, we have argued that conversational interactions involve several layers of joint commitments), including at least the joint commitments involved in carrying out the current interaction, and those that are constitutive of what we call "joint meaning" (Carassa and Colombetti 2009a, 2009b, 2011, in press).

Given the importance that we attribute to joint commitments in a theory of communicative interactions, it is crucial to explain how such commitments are created by the interlocutors. This brings us to the last issue we want to discuss, namely, communicative intentions.

\section{Communicative intentions}

Communicative intentions are a controversial concept. Modeled after Paul Grice's meaning intentions (1957), in one form or another they have been considered as a crucial component of communication by many authors, including Strawson (1964), Searle (1969), Schiffer (1972), and Bach and Harnish (1979). On the contrary, most authors who concentrate on the normative aspect of communication neglect them completely (Brandom 1994; Kukla and Lance 2009), or consider them somewhat marginal (Alston 2000).

In our opinion, a problem of all theories that give communicative intentions a central role is that it is not at all clear what function they are supposed to serve. Many people find it intuitively convincing that when agents communicate something they hold both a first-level intention to achieve some effect, and a second-level intention that the recognition of their first-level intention (or the recognition of both the first-level and the second-level intention, in the reflexive version of communicative intentions) plays a role in achieving the effect. But why exactly is such a complex cognitive structure required for communication? What function does it serve? To our knowledge, no existing theory of 
human communication has a cogent answer to these questions, and cognitive pragmatics is no exception.

Our thesis is that communicative intentions are functional to the construction of interpersonal normativity. The basic idea is that simply holding an intention somehow involving another agent, and having such an intention recognized by the other agent, is not sufficient to bring in normative relationships. To defend this point of view, we shall rely on another example. Suppose that a tourist needs some help to find a location in a foreign town but is too shy to ask. The tourist could ostensibly look at her street map with a puzzled expression; in many countries, passersby will soon offer their help. Now, what is the difference between this behavior and explicitly asking for help?

By intentionally showing puzzlement, the tourist counts on the helpfulness of others to receive help. By explicitly requesting help from a passerby, the tourist displays not only her intention to receive help, but also her intention that the former intention be recognized. By doing so, the tourist precommits to carry out an information-exchange interaction with the passerby; that is, the tourist puts herself in such a position that the passerby's acceptance of the request is now sufficient to create a joint commitment of the tourist and the passerby to the effect that the interaction is carried out. That this is the case is shown, for instance, by the fact that it would be inappropriate for the tourist to ask for information and then saying that she does not need help, while saying so would be acceptable in the former situation, where no explicit request for help is made.

\section{Conclusions}

We share with Bara the core assumption that human communication should be regarded as a cooperative activity, and that the crucial goal for a theory of communication is to understand what goes on in the minds of the interlocutors. However, we have argued that the theoretical framework of cognitive pragmatics in insufficient, and that a major pitfall of the theory is that it does not recognize the essential role of normativity.

Neglecting the role of normativity in human interactions has been a common pitfall in cognitive science. This may be partly due to the fact that we still lack a widely accepted treatment of normative cognition, comparable to the existing theories of epistemic and volitional cognition. Moreover, philosophers and psychologist interested in normativity typically concentrate on superpersonal norms, like those characteristic of morality or law, and disregard interpersonal normativity, which, in our view, plays a crucial role in human communicative interactions. 
As of today, there is a sharp separation between two types of theories of human communication: (1) naturalistic theories, like cognitive pragmatics, in which communication is essentially reduced to expressing and recognizing certain epistemic and volitional mental states, and (2) normativistic theories, like Alston's version of speech act theory (2000) and Kukla and Lance's pragmatism (2009), which recognize the crucial importance of normativity. If we are on the right track, however, there is no reason why naturalists and normativists should sit on opposite sides. A unified approach to communication is possible, if only the naturalistic nature of normativity is taken seriously. In our opinion, the key to a successful integration of the two types of theories lies in the key role played by communicative intentions in the creation of joint commitments.

\section{References}

Alston, William P. 2000. Illocutionary acts and sentence meaning. Ithaca, NY: Cornell University Press.

Bach, Kent \& Robert M. Harnish. 1979. Linguistic communication and speech acts. Cambridge, MA: MIT Press.

Bara, Bruno G. 2010. Cognitive pragmatics: The mental processes of communication. Cambridge, MA: The MIT Press.

Bara, Bruno G. 2011. Cognitive pragmatics: The mental processes of communication. Intercultural Pragmatics 8(3). 443-485.

Brandom, Robert B. 1994. Making it Explicit. Cambridge, MA: Harvard University Press.

Carassa, Antonella \& Marco Colombetti. 2009a. Joint meaning. Journal of Pragmatics 41(9). 1837-1854.

Carassa, Antonella \& Marco Colombetti. 2009b. Situated communicative acts: A deontic approach. Proceedings of the $31^{\text {st }}$ Annual Meeting of the Cognitive Science Society (CogSci 2009), Amsterdam, 1382-1387.

Carassa, Antonella \& Marco Colombetti. 2011. Layers of joint commitments in interpersonal communication. Proceedings of the 33 ${ }^{\text {rd }}$ Annual Meeting of the Cognitive Science Society (CogSci 2011), Boston, 1055-1060.

Carassa, Antonella \& Marco Colombetti. In press. Creating interpersonal reality through conversational interactions. In Hans Bernhard Schmid, Beatrice Kobow, \& Michael Schmitz (eds.), The background of social reality. Berlin: Springer.

Carassa, Antonella, Francesca Morganti, \& Marco Colombetti. 2008. The role of joint commitment in intersubjectivity. In Francesca Morganti, Antonella Carassa, \& Giuseppe Riva (eds.), Enacting intersubjectivity: A cognitive and social perspective on the study of interactions. Amsterdam: IOS Press, 187-201.

Gilbert, Margaret P. 1989. On social facts. New York: Rutledge.

Gilbert, Margaret P. 1996. Living together: Rationality, sociality, and obligation. Lanham MD: Rowman \& Littlefield.

Gilbert, Margaret P. 2000. Sociality and responsibility: New essays in plural subject theory. Lanham, MD: Rowman \& Littlefield.

Grice, H. Paul. 1957. Meaning. The Philosophical Review, 66(3). 377-388. 


\section{0}

Kukla, Rebecca \& Mark Lance. 2009. Yo! and Lo! The pragmatic topography of the space of reasons. Cambridge, MA: Harvard University Press.

Machery, Edward \& Ron Mallow. 2010. Evolution of morality. In John M. Doris (ed.), Handbook of moral psychology, 3-46. Oxford: Oxford University Press.

Roth, Abraham S. 2010. Shared agency. Stanford Encyclopedia of Philosophy, http://plato. stanford.edu/entries/shared-agency/ (accessed 13 November 2011).

Schiffer, Stephen R. 1972. Meaning. Oxford: Oxford University Press.

Searle, John R. 1969. Speech acts: An essay in the philosophy of language. Cambridge: Cambridge University Press.

Searle, John R. 2007. What is language: Some preliminary remarks. In Savas L. Tsohatzidis (ed.), John Searle's philosophy of language: Force, meaning, and mind, 15-48. Cambridge: Cambridge University Press.

Strawson, Peter F. 1964. Intention and convention in speech acts. The Philosophical Review 73(4). 439-460.

Tollefsen, Deborah. 2004. Collective Intentionality. Internet Encyclopedia of Philosophy, http:// www.iep.utm.edu/coll-int/ (accessed 13 November 2011).

Tomasello, Michael. 2008. Origins of human communication. Cambridge, MA: MIT Press.

Correspondence address: marco.colombetti@usi.ch 